\title{
Open access fibresigmoidoscopy: a comparative audit of efficacy
}

\author{
L KALRA， W R PRICE， B J M JONES， A N HAMLYN
}

\begin{abstract}
A total of 541 open access referrals for fibresigmoidoscopy over five years were compared with $\mathbf{4 9 5}$ hospital initiated procedures during the same period. The number of open access fibresigmoidoscopies doubled during the five years but diagnostic yield remained unchanged at about $40 \%$ and was similar to that of the hospital initiated procedures. Colorectal carcinoma was seen in 64 open access patients compared with 47 hospital referred patients, the proportion of Dukes's type A lesions being similar (34\%) in both groups. Polyps, colitis, and diverticular disease were equally common in open access and hospital referred patients. Fibresigmoidoscopy failed to detect disease in only 12 patients $(1 \cdot 2 \%)$ and the procedure was unsatisfactory in only 54 . Referral was considered justified in $475(88 \%)$ open access patients, and only $54(17 \%)$ patients with normal appearances at endoscopy required further investigations.

Diagnostic yields were low $(19 \% ; 30 / 156$ cases $)$ in open access patients under 40 and in patients with abdominal pain, constipation, or abdominal pain with constipation (0-17\%). Most of these young patients presumably suffer from the irritable bowel syndrome and do not justify fibresigmoidoscopy. In contrast, there was a high diagnostic yield $(90-100 \%)$ in patients of all ages referred for diarrhoea and rectal bleeding, altered blood from the rectum, and rectal bleeding associated with abdominal pain.
\end{abstract}

Open access fibresigmoidoscopy is an effective service that should be freely available to general practitioners.

\section{Introduction}

Direct general practitioner referrals for endoscopic investigations (open access services) may be expected to result in increased detection of diseases of the gut and reduced delay and cost associated with specialist referral. We present an audit of an open access fibresigmoidoscopic service over five years aimed at $(a)$ an objective assessment of the effectiveness of open access fibresigmoidoscopy as compared with hospital initiated procedures and $(b)$ the determination of patient characteristics that best discriminate for disease.

\section{Patients and methods}

All patients referred for fibresigmoidoscopy for the first time during the five years 1982-6 were included in the study. Open access referrals were defined as patients seen for the first time during the procedure and in whom no examination or investigations had previously been undertaken. Hospital inpatients referred for fibresigmoidoscopy or patients attending the outpatient department for colorectal symptoms in whom results of other investigations were available constituted the hospital initiated group. The Dudley Health District has an estimated catchment population of 296000 .

Patients attended the endoscopy unit on the day of examination. Though overnight bowel preparation was not advised routinely, a few patients were

Department of Gastroenterology, Russells Hall and Wordsley Hospitals, Dudley, West Midlands

L KALRA, MRCP, medical registrar

W R PRICE, PHD, MRCGP, clinical assistant

B J M JONES, MD, MRCP, consultant gastroenterologist

A N HAMLYN, BSC, FRCP, consultant gastroenterologist

Correspondence to: $\operatorname{Dr}$ A N Hamlyn, Wordsley Hospital, Stourbridge DY8 5QX. given an enema before examination. The endoscopy team consisted of two physician specialists and two trained generalists (one clinical assistant, one registrar) devoting three sessions a week to open access endoscopy. Patients were not sedated, and a $60 \mathrm{~cm}$ fibresigmoidoscope (Olympus OSF or CFP10S) was used. Examination was deemed a failure if in the absence of disease the rectosigmoid junction could not be negotiated

Medical records were perused for details of patients, investigations, and final outcome. Variables assessed included diagnostic yield, failure rate, complications, operator variability, and appropriateness of referral for fibresigmoidoscopy. Referral data were also analysed for discriminants associated with abnormal findings. Results were analysed by $\chi^{2}$ test with Yates's correction

\section{Results}

Over the five years 1036 patients had fibresigmoidoscopy for the first time. Of these, $541(52 \%)$ were open access referrals and 495 (48\%) hospital referrals. Table I shows the yearly distribution.

In the open access patients the male to female ratio was 35:65, whereas in the hospital referred group the ratio was 47:53 $(p<0 \cdot 001)$. Abdominal pain was the commonest cause of open access referral, followed by diarrhoea, rectal bleeding, and constipation. In the hospital referred group diarrhoea and rectal bleeding were the commonest symptoms (table II).

Abnormalities were detected at $216(40 \%)$ of the open access fibresigmoidoscopies and $218(44 \%)$ of the hospital initiated procedures. Yearly yields varied from $31 \%$ ( $21 / 68$ cases) to $43 \%$ (51/119) in the open access group but increased steadily from $37 \%(29 / 79)$ to $54 \%(53 / 99)$ in the hospital initiated group. This rise, however, was not statistically significant. The yields of colorectal carcinoma, polyps, colitis, and diverticular disease were similar in open access and hospital referred patients (table III).

Fibresigmoidscopy was unsuccessful in 54 patients (open access 31, hospital initiated 23) by our criteria. The commonest cause of failure to negotiate the rectosigmoid junction was faecal loading, the other cause being distortion of anatomy by severe diverticular disease. Bowel disease was initially missed in seven open access patients (carcinoma in four, polyps in three) and five hospital referred patients (carcinoma in three, polyps in one, angiodysplasia in one). Of the missed lesions, three colorectal carcinomas and two polyps were diagnosed by barium enema studies. The other four carcinomas and two polyps were seen on colonoscopy. Angiodysplasia was diagnosed by arteriography.

There was no appreciable variability among the operators in the study. The diagnostic yields, failure rate, and number of missed lesions were similar for specialist and non-specialist endoscopists.

Severe complications were not encountered. Some patients complained of mild to moderate discomfort, bloating, and abdominal pain. Discomfort severe enough to warrant terminating the examination did not occur in any patient.

Analysis of referral symptoms showed an increased incidence of bowel disease in patients referred for diarrhoea and rectal bleeding $(91 \% ; 215 / 237)$, passage of altered blood from the rectum $(95 \% ; 37 / 39)$, and rectal bleeding associated with abdominal pain (12/12). Low yields were associated with abdominal pain alone (nil), constipation alone $(17 \% ; 9 / 54)$, and abdominal pain with constipation $(8 \% ; 5 / 61)$ (table II).

TABLE I-Yearly distribution of first time open access and hospital initiated fibresigmoid oscopies

\begin{tabular}{lcccccc}
\hline & \multicolumn{2}{c}{ Open access procedures } & & \multicolumn{2}{c}{ Hospital initiated procedures } \\
\cline { 2 - 3 } \cline { 6 - 7 } Year & Total & $\begin{array}{c}\text { No (\%) showing } \\
\text { abnormality }\end{array}$ & & Total & $\begin{array}{c}\text { No (\%) showing } \\
\text { abnormality }\end{array}$ \\
\hline 1982 & 68 & $21(30 \cdot 9)$ & & 79 & $29(36 \cdot 7)$ \\
1983 & 84 & $34(40 \cdot 5)$ & & 97 & $36(37 \cdot 1)$ \\
1984 & 118 & $46(39 \cdot 0)$ & & 106 & $44(41 \cdot 5)$ \\
1985 & 119 & $51(42 \cdot 9)$ & & 114 & $56(49 \cdot 1)$ \\
1986 & 152 & $64(42 \cdot 1)$ & & 99 & $53(53 \cdot 5)$ \\
\hline Total & 541 & $216(39 \cdot 9)$ & & 495 & $218(44 \cdot 0)$ \\
\hline
\end{tabular}


TABLE II-Referral symptom analysis for discriminants associated with abnormal findings in open access and hospital initiated patients

\begin{tabular}{|c|c|c|c|c|}
\hline Symptoms & $\begin{array}{c}\text { Total } \\
\text { patients }\end{array}$ & $\begin{array}{l}\text { Open access } \\
\text { group }\end{array}$ & $\begin{array}{c}\text { Hospital } \\
\text { initiated group }\end{array}$ & $\begin{array}{l}\text { No (\%) with } \\
\text { diagnostic yield }\end{array}$ \\
\hline Diarrhoea & 252 & 109 & 143 & $96(38 \cdot 1)$ \\
\hline Rectal bleeding & 104 & 48 & 56 & $49(47 \cdot 1)$ \\
\hline Fresh blood & 65 & 33 & 32 & $12(18 \cdot 5)$ \\
\hline Altered blood & 39 & 15 & 24 & $37(94 \cdot 9)$ \\
\hline Constipation & 54 & 32 & 22 & $9(16 \cdot 7)$ \\
\hline Abdominal pain & 201 & 187 & 14 & 0 \\
\hline $\begin{array}{l}\text { Diarrhoea and rectal } \\
\text { bleeding }\end{array}$ & 237 & 88 & 149 & $215(90 \cdot 7)$ \\
\hline Diarrhoea and & & & & \\
\hline abdominal pain & 90 & 28 & 62 & $23(25 \cdot 6)$ \\
\hline $\begin{array}{l}\text { Rectal bleeding and } \\
\text { abdominal pain }\end{array}$ & 12 & 10 & 2 & $12(100 \cdot 0)$ \\
\hline $\begin{array}{l}\text { Rectal bleeding and } \\
\text { constipation }\end{array}$ & 25 & 1 & 24 & $25(100 \cdot 0)$ \\
\hline $\begin{array}{l}\text { Constipation and } \\
\text { abdominal pain }\end{array}$ & 61 & 38 & 23 & $5 \quad(8 \cdot 2)$ \\
\hline
\end{tabular}

TABLE III-Abnormal findings in open access and hospital referrals. (Figures are numbers (percentages) of patients)

\begin{tabular}{lcc}
\hline Diagnosis & Open access group $(\mathrm{n}=216)$ & $\begin{array}{c}\text { Hospital initiated } \\
\text { group }(\mathrm{n}=218)\end{array}$ \\
\hline Carcinoma & $64(29 \cdot 6)$ & $47(21 \cdot 6)$ \\
Dukes's type A & 22 & 16 \\
Dukes's type B & 26 & 21 \\
Dukes's type C & 16 & 10 \\
Polyps & $82(38 \cdot 0)$ & $85(39 \cdot 0)$ \\
Colitis & $41(19 \cdot 0)$ & $59(27 \cdot 1)$ \\
Diverticular disease & $21(9 \cdot 7)$ & $22(10 \cdot 1)$ \\
Solitary rectal ulcer & $5(2 \cdot 3)$ & $3(1 \cdot 4)$ \\
Angiodysplasia & $3(1 \cdot 4)$ & $2(0 \cdot 9)$ \\
\hline
\end{tabular}

There were 156 patients (29\%) under age 40 in the open access group and $82(17 \%)$ under 40 in the hospital referred group $(\mathrm{p}<0.001)$. Diagnostic yield was significantly lower among the open access patients $(n=30 ; 19 \%)$ than among the hospital referred patients $(36 ; 44 \%)$ in this age group $(p<0.001)$. In contrast, the diagnostic yield among open access and hospital referred patients aged over 40 was comparable $(48 \%(186 / 385) v 44 \%$ (182/413)). Colorectal carcinoma was not seen in patients under 40 , the commonest abnormality being colitis.

Study of referral letters and patients' records showed that fibresigmoidoscopy would have been offered to $475(88 \%)$ of the 541 open access patients on our original reference criteria even if previously assessed in the clinic. Further hospital appointments or investigations were required in only 54 of the 325 patients $(17 \%)$ with normal endoscopic findings, the rest being discharged after the procedure.

\section{Discussion}

Accounts of open access endoscopic services have suggested that they are feasible, with evidence of appropriate detection rates of abnormality, negligible complications, and satisfactory tolerance. ${ }^{12}$ Nevertheless, it has also been concluded that the increase in numbers of endoscopies performed as a result of introducing such a service cannot be justified. ${ }^{3}$ This may not necessarily be true for fibresigmoidoscopy, as in our series the diagnostic yield remained constant at around $40 \%$ despite increased direct referrals and would have been higher given appropriate referral criteria.

Although overall diagnostic yield was as high in open access procedures as in hospital referrals, it is clear that it could be considerably improved in view of the low yield among open access patients under 40 and in those with abdominal pain or constipation alone as the reason for referral. The higher proportion of women in the open access group is consistent with the inclusion of many patients with presumed irritable bowel syndrome, in whom this investigation is probably unjustified under the age of 40 . In contrast, the high diagnostic yield among patients of all ages referred for diarrhoea and rectal bleeding is encouraging. We believe that modifying our original criteria for referral could reduce open access referral by $38 \%$ and increase diagnostic yield by $25 \%$ without adversely affecting sensitivity of the procedure.
Screening for colorectal carcinoma is an important consideration in open access fibresigmoidoscopy. Almost $70 \%$ of colorectal neoplasms occur within the reach of a $60 \mathrm{~cm}$ fibresigmoidoscope, and endoscopy has been shown to be superior to barium enema studies for investigating the distal colon. ${ }^{56}$ Though the yield of colorectal carcinomas was $8 \%$ higher in open access patients (table III), this difference failed to achieve significance. More important, Dukes's type A lesions were seen in one third of these patients, suggesting that widespread availability and utilisation of open access fibresigmoidoscopic services might contribute significantly to the diagnosis of early colorectal carcinoma and eventually reduce mortality.

Disease was missed in only 12 patients $(1 \cdot 2 \%)$ having fibresigmoidoscopy. We are, however, concerned that seven of the 118 colorectal carcinomas within the reach of a fibresigmoidoscope were missed during the initial examination. The unprepared state of the bowel might have contributed, and a routine phosphate enema before examination may improve detection.

From our experience the costs of providing open access services would compare favourably with more conventional methods of investigating colorectal symptoms. Direct referral for endoscopy obviated the need for initial outpatient referral in all patients. Further appointments or investigations were required in only half of all patients seen, thus saving outpatient time and expense. Hospital Activity Analysis data have shown a $70 \%$ fall in the numbers of open access barium enema examinations, from 151 in 1982 to 44 in 1986. Though the cost of endoscopy is similar to that of barium studies, ${ }^{8}$ fibresigmoidoscopy has the advantage of sensitivity and the ability to yield a tissue diagnosis.

In assessing effectiveness the overall benefit of excluding carcinoma or serious disease also needs to be taken into account. ${ }^{9}$ As many as $273(84 \%)$ open access patients with normal endoscopic findings were reassured and did not require further follow up, saving the cost of repeated hospital and general practice consultations, prescribing, further investigations, and time lost from work.

A steady increase in the number of open access fibresigmoidoscopies was seen, which more than doubled over the five years. Because of existing limitations of endoscopic facilities and endoscopists' time, management of the increase in workload required maximal utilisation of available resources. We achieved this by training clinical assistants and registrars in diagnostic endoscopic techniques. Our results suggest that satisfactory training at district general hospital level is possible, the fundamental requirement being competence in technique and interpretation. ${ }^{10}$

We conclude that open access fibresigmoidoscopy is an effective service which should be freely available to general practitioners. All patients presenting with persistent, troublesome diarrhoea and rectal bleeding should be referred for endoscopy. Discretion should be exercised in patients under 40 and those with abdominal pain and constipation. Close liaison between general practitioners and gastroenterologists is important and criteria for referral should be reviewed periodically, taking into account not only the possibility of disease but also the consequences of diagnostic uncertainty.

\section{References}

1 Fisher JA, Surridge JG, Vartan CP, Loehry CA. Upper gastrointestinal endoscopy: a GP service. BrMed f 1977;ii:1199-201.

2 Beavis AK dyspepsia. BrMed f 1979;i:1387-9.

Holdstock G, Wiseman M, Loehry CA. Open access endoscopic service for general practitioners BrMed J 1979;i:457-9.

4 Winnawer SJ. Prevention, screening and early diagnosis of large bowel cancer. In: DeCosse JJ, ed. Large bowel cancer. Edinburgh: Churchill Livingstone, 1981:46-60.

5 Farrands PA, Vellacot KD, Amar SS, et al. Flexible fibreoptic sigmoidoscopy and double contras barium enema examination in the identification of adenomas and carcinoma of the colon Dis Colon Rectum 1983;26:725-7.

6 Albridge MC, Simms AJW. Colonoscopic findings in patients without $\mathrm{x}$-ray evidence of colonic neoplasm. Lancet 1986;ii:833-4.

7 Funch DP. Diagnostic delay in symptomatic colorectal carcinoma. Cancer 1985;56:785-6.

8 Stilwell JA. The cost of x-rays. Br J Radiol 1984;57:647-9.

9 Jones R. Open access endoscopy. Br Med f 1985;291:424-6.

10 Dagradi AE. Who should do gastrointestinal endoscopy? Am 7 Gastroenterol 1985;80:658.

(Accepted 14 fanuary 1988) 